\title{
Anterior Cervical Interbody Fusion : Comparison Study between Simple Fusion, Locked and Non-Locked Plating Systems
}

\author{
Chun-Kun Park, Kyung-Suk Cho, Byung-Chul Son, \\ Young-Geun Choi, Kwan-Sung Lee, Joon-Ki Kang
}

\author{
Department of Neurosurgery \\ College of Medicine, The Catholic University of Korea \\ Seoul, Korea
}

\begin{abstract}
The use of metallic plate and screws in the anterior cervical fusion has become accepted and popular. There exist two different plating systems. However, there has been few attempt to compare surgical morbidity and clinical results either between anterior cervical fusion with and without a plating system or between two different systems in a single series of clinical study.

The authors reviewed 117 patients undergoing anterior cervical fusion during the period of January 1992 to September 1996. Simple fusion without a plating system was applied in 55 (group 1), a bicortical non-locked plate screw system in 25 (group 2), and a monocortical locked plate screw system in 37 (group 3). The average follow-up period was about 13.2 months. In group 1, twenty-two patients (40\%) with fracture-dislocation or corpectomy required a rigid brace such as halo brace and Minerva cast for 3 months postoperatively and seven patients (13\%) experienced graft complications, mainly graft extrusion, while in groups 2 and 3, the patients required only a soft brace for 4 to 8 weeks and no patient experienced serious graft complications like graft extrusion. But two patients of screw breakage, two patients of screw back-out and one patient of non-union were observed in group 2. In comparison of the clinical complications such as hoarseness, there were no significant differences between the groups.

In conclusion, a plating system in anterior cervical fusion appears to be safe in spite of its technical demands during the surgery, and to offer postoperative stability in the spine and early ambulation without a rigid brace. A monocortical locked plate screw system appears to have less hardware failure and better surgical results than a bicortical non-locked plate screw system.
\end{abstract}

Key word: anterior cervical interbody fusion, cervical plate and screws, allograft, B.O.P., complication

Spinal Surgery $13(2): 107 \sim 118,1999$

(Received : January 20, 1998, Accepted : June 14, 1999)

Address reprint request to: Chun-Kun Park, M.D., Department of Neurosurgery, Kangnam St. Mary's Hospital, Catholic University Medical College, 505, Banpodong Seocho-ku, Seoul, 137-040, Korea 


\section{INTRODUCTION}

The anterior approach to the lower cervical spine was utilized to treat various cervical spine diseases $[13,26,29]$. The majority of anterior cervical procedures are still performed to treat degenerative disease, however any lesion anterior to the cervical spinal canal can be approached via this procedure [14, $17,33,34]$. In patients treated with an anterior cervical procedure, postoperative immobilization is often desired. A rigid brace must be needed even following simple anterior discectomy when there is preoperative instability. Traumatic injuries requiring an anterior decompression often need postoperative cervical halo immobilization as they are usually associated with severe posterior element disruption and/or ligamentous injury [1, 32, 33, 34]. Anterior cervical plate fixation can significantly decrease or eliminate the need for external immobilization prior to the development of a solid bony fusion.

A variety of plating system have been utilized since Orozco and Llovet first described the application of a stainless steel plate for anterior cervical osteosynthesis in 1970 [23]. There were many improvements in the plates, screws, and instrumentations necessary to apply this technology. Recently, there exist two markedly different instrumentation systems for anterior cervical spine: the one, bicortical non-locked plate screw system (BNPS) and the other, monocortical locked plate screw system (MLPS). Although the clinical effectiveness of these systems has been established in the treatment of various cervical spine diseases, it must be of use to perform a comparison study of surgical morbidity and clinical course between the anterior cervical procedures with and without the plating systems as well as between two different plating systems.

The purpose of this retrospective clinical review was to establish whether there were differences in clinical factors such as surgical complication, hospital stay and surgical outcome between anterior cervical fusion with and without a plating system, and to document the impact of mono- and bi-cortical plating systems use on these clinical factors.

\section{MATERIALS AND METHODS}

A retrospective study of patients undergoing anterior cervical fusion was performed. One hundred seven-teen patients were operated on by the first author (CKP) between January 1992 and September 1996. The criteria for anterior cervical fusion in the current study were insufficiency of the anterior column of the lower cervical spine caused by fractures, tumors or infection, multiple decompression procedures such as discectomy, uncectomy and vertebrectomy, a pathology in the anterior column with simultaneous posterior instability and complications of a grafted material. The patients were composed of three groups in chronological order and according to surgical method. Between January 1992 and December 1993, anterior cervical fusion was performed without a plating system in fifty-five patients (group 1), between January 1994 and June 1994, internal fixation procedure was done with BNPS (Top, Fheling, Germany) after anterior cervical fusion in twenty-five (group 2) (Figure 1) and between July 1994 and September 1996, with MLPS (Orion, Danek, USA) in thirty-seven (group 3) (Figure 2). The mean clinical follow-up period was 13.2 months (range, 6-25 months). During the follow-up period, the patients were examined clinically as well as radiographically. The clinical follow-up was focused mainly upon the comparison of surgical morbidity such as surgical and graft complications and hardware failures, but not focused upon the comparison of clinical outcome like neurological and functional results, because the present retrospective study included various cervical spine diseases and it should be incongruent to compare the clinical outcome in this kind of clinical review. The data of surgical complications were analyzed with chi-square test and $\mathrm{P}$ values less than 0.05 were considered significant. 


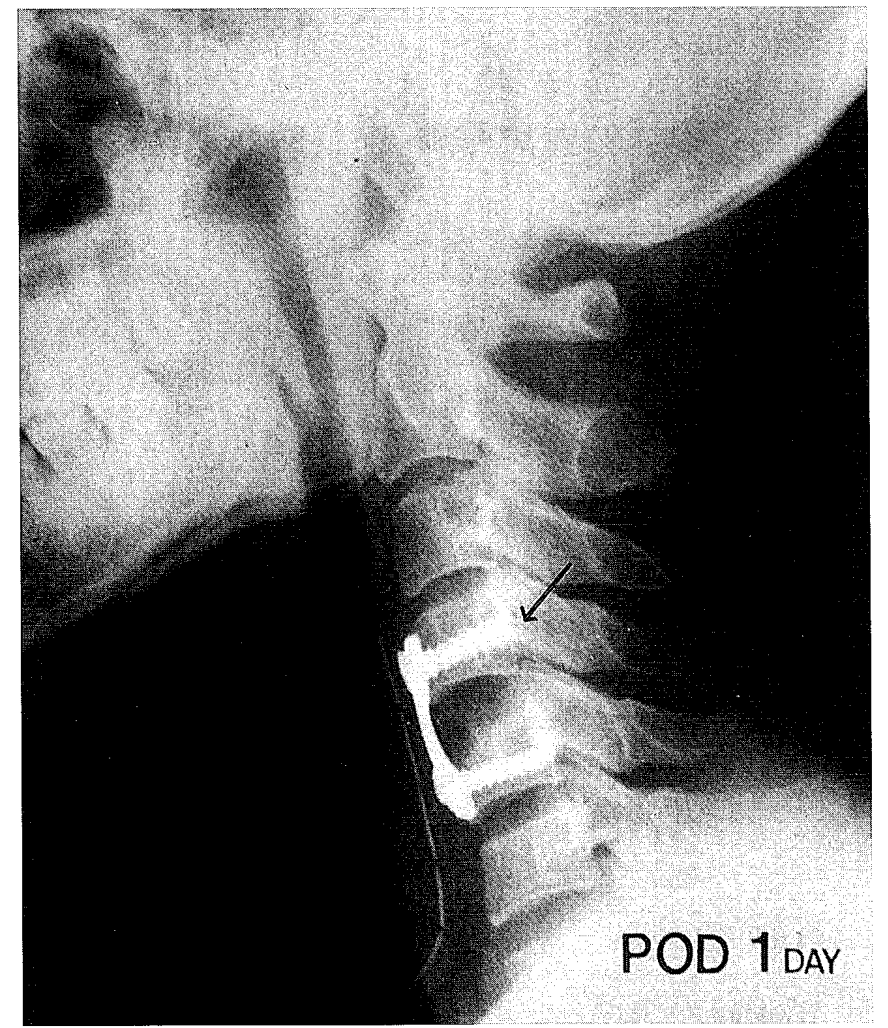

Figure 1. Immediate postoperative radiograph of 27-year-old man operated with bicortical nonlocked plate screw system and B.O.P. interbody graft due to traumatic $\mathrm{C} 4-5$ subluxation. Note the screws piercing the dorsal cortex of the vertebral body (arrow) and radiolucency of B.O.P.

\section{< Surgical Technique >}

The Cloward's technique was used in 39 discectomy sites, the Smith-Robinson's technique was in 106 discectomy sites, and corpectomy in 43 operative cases. Three kinds of graft materials were used: autograft from the iliac crest in 23 operative sites, fibular allograft (Tutoplast, Biodynamics, Germany) in 46, and B.O.P. (biocompatible osteoconductive polymer; DTI Medical, Belgium) in 64. Removal of disc material, ossified posterior longitudinal ligament and foraminal osteophytes was performed using microscope visualization. All the surgical procedures were undergone via the right anterior medial approach except two cases with a lesion in the cervico-thoracic junction, in which the right supraclavicular approach was applied.

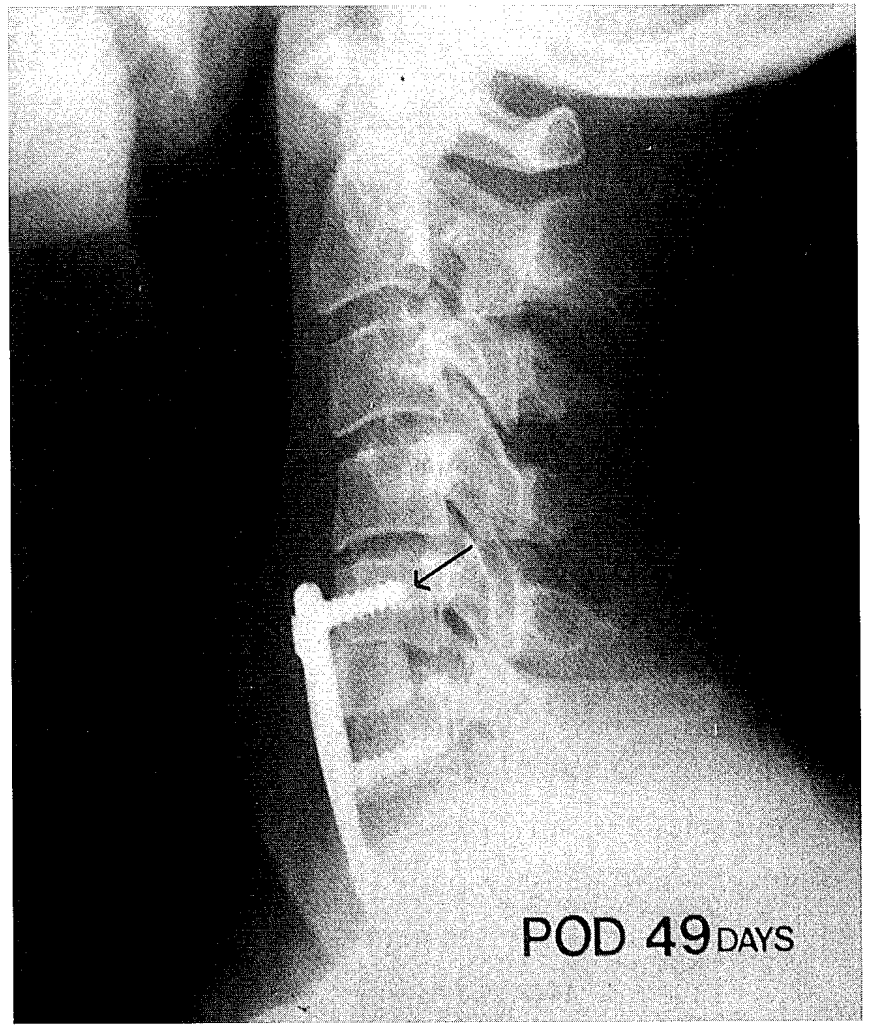

Figure 2. Postoperative radiograph of 43-yearold woman operated with monocortical locked plate screw system and fibular allograft due to C5-6 and C6-7 HNP. Note the screws not piercing the dorsal cortex of the vertebral body (arrow).

\section{RESULTS}

Background data of the three groups such as demographics were similar in the study. Mean age was 43.5 years (range, 17-72) in group 1, 45.7 years (range, 22-68) in group 2, and 47.2 years (range, 2170 ) in group 3 (Table 1). About $80 \%$ of the patients were man in each group (Table 2). About $1 / 3$ of the patients were operated on due to traumatic fracturedislocation, about $1 / 3$ were due to cervical spondylosis and OPLL, and the remaining $1 / 3$ were due to multiple cervical discs and/or instability in each group (Table 3). In all groups, the most common stabilized segments were C4-5, C5-6 and C6-7. 
Table 1. Age distribution

\begin{tabular}{|c|c|c|c|c|c|c|}
\hline \multirow{2}{*}{\multicolumn{2}{|c|}{ Surgical Method $^{*}$}} & \multicolumn{4}{|c|}{ Age } & \multirow{3}{*}{$\begin{array}{l}\text { Total } \\
55\end{array}$} \\
\hline & & \multirow{2}{*}{$\frac{<20}{4}$} & \multirow{2}{*}{$\frac{21-40}{14}$} & \multirow{2}{*}{$\frac{41-60}{31}$} & \multirow{2}{*}{$\frac{>60}{6}$} & \\
\hline Without & $\mathrm{P} / \mathrm{S}$ & & & & & \\
\hline \multicolumn{2}{|c|}{ Non-locked P/S } & & 8 & 14 & 3 & 25 \\
\hline Locked & $\mathrm{P} / \mathrm{S}$ & & 15 & 17 & 5 & 37 \\
\hline Total & & 4 & 37 & 62 & 14 & 117 \\
\hline
\end{tabular}

\section{< Perioperative Variables >}

No patient in any group required transfusion except two corpectomy patients. Discharge for the patients with cervical discs generally occurred on the third or fourth postoperative day. Average length of stay in the patients without trauma was 8.7 days in group 1 and about 4 days in groups 2 and 3 .

Postoperative Management. $40 \%$ of the patients were managed with rigid cervical braces such as halo vest, Minerva cast and Somi brace for 3 months in group 1, however no patient was managed with a rigid brace in group 2 or $3.60 \%$ and $73 \%$ of the patients needed a soft brace such as Philadelphia collar for less than 8 weeks in groups 2 and 3 respectively, while 18 of 33 patients $(54 \%)$ who were managed with a soft brace in group 1 needed it for more than 8 weeks (Table 4).

\section{< Surgical Complication >}

The surgical complications were reviewed by three categories: clinical symptoms and signs, graft complications, and hardware failures. There were no significant differences in the clinical symptoms and signs between the groups, but it appeared that increased neck pain, foreign body sensation on swallowing and dysphagia were noted mainly in the patients treated with a plating system (groups 2 and $3)$. In case of graft complication, graft extrusion occurred significantly more in group $1(\mathrm{P}<0.05$; chisquare test), while graft settling appeared to occur more in groups 2 and 3 . There was no hardware
Table 2. Sex distribution

\begin{tabular}{lcccc}
\hline \multicolumn{2}{l}{ Surgical Method $^{*}$} & Male & Female & Total \\
\hline Without $\quad$ P/S & 44 & 11 & 55 \\
Non-locked P/S & 20 & 5 & 25 \\
Locked $\quad$ P/S & 28 & 9 & 37 \\
\hline \multicolumn{2}{c}{ Total } & 92 & 25 & 117 \\
\hline
\end{tabular}

${ }^{2} \mathrm{P} / \mathrm{S}$ : plate and screws

failure in the patients operated with MLPS (group 3), while there were two cases of screw fracture, two cases of screw back-out and one case of nonunion in BNPS (group 2) (Table 5), but no patient with hardware failure needed reoperation.

\section{DISCUSSION}

This study has certain limitations because of its retrospective design. The most important shortcoming of this study was that there were incomparable variables observed in the groups. Especially, there were various fusion methods and graft materials used in surgical procedures in each group. However, the current study may present an overview of the anterior approach to the cervical spine in lower cervical spine diseases. To our 

Non-Locked Plating System

Table 3. Diagonsis in $\mathbf{1 1 7}$ patients undergoing anterior cervical interbody fusion

\begin{tabular}{lccc}
\hline & \multicolumn{3}{c}{ Surgical Method } \\
\cline { 2 - 4 } Diagnosis & Without P/S & Non-locked & Locked P/S \\
\hline Trauma & 15 & 6 & 16 \\
fracture and/or dislocation & 17 & 7 & 8 \\
Cervical spondylosis \& OPLL & & & \\
corpectomy \& discectomy & & 9 & 12 \\
Cervical HNP & & & \\
multiple levels or instability & 23 & 3 & 1 \\
graft complication & & 25 & 37 \\
Cervical spine tumor & & & \\
corpectomy & 55 & & \\
\hline Total & & & \\
\hline
\end{tabular}

* OPLL: ossified posterior longitudinal ligament

HNP: herniated nucleus pulposus

Table 4. Postoperative application of orthoses

\begin{tabular}{lccc}
\hline & \multicolumn{3}{c}{ Surgical Method (number of patients) } \\
\cline { 2 - 3 } Orthoses & 9 & & \\
\hline Walo vest* & 11 & & \\
Minerva cast* & 2 & & 10 \\
Somi brace* & & 10 & 27 \\
Philadelphia collar & 18 & 15 & 27 Locked P/S (37) \\
more than 8 weeks & 15 & & \\
less than 8 weeks & & & \\
\hline
\end{tabular}

* Immobilization for about 3 months postoperatively. 
knowledge, this study of the comparison not only between anterior cervical fusion with and without a plating system but between BNPS and MLPS in a single series is the first one in the English literature.

Nowadays, the anterior approach to achieving fusion of the lower cervical spine has become an accepted and popular approach. Although the technique of an anteriorly applied graft has been widely used in achieving fusion in various cervical spine diseases, this technique has been plagued with complications especially in acute cervical spine injury with instability [30,32]. Reported complications include migration of the graft, creating instability, and failure to maintain the spine in a reduced position. These problems have required the immobilization of the cervical spine for augmentation with additional methods such as the use of a halo device or Minerva cast and additional posterior cervical surgical stabilization. However, these alternatives create less than ideal situations with regard to early patient mobilization and rehabilitation. It has been reported that graft displacement occurs in as many as $8 \%$ of the patients who undergo surgery for disc herniation and spondylosis [28]. The results obtained in our study revealed that the rate of graft migration was still higher in the patients treated with simple cervical fusion than the others managed with a plating system ( $9 \%$ vs. $0 \%$ ), even if they were immobilized with a rigid external brace and required a late postoperative mobilization. The need for cervical immobilization following an anterior plating procedure is somewhat controversial. Although the use of postoperative immobilization is not universal, most surgeons recommend some type of external cervical support $[2,7,8,9,19,22,24,25,31]$. The need for postoperative external bracing is best addressed in a case-by-case manner. We recommend young and healthy patients with only posterior instability to wear a soft collar for 4 to 6 weeks, whereas older individuals and patients with serious preoperative instability were recommended to wear a soft collar for 8 to 12 weeks.

It was in the European literature that the first reports of anterior metallic fixation of the cervical spine were described. In 1970, Orzco and Llover described the application of a stainless steel AO small fragment plate for anterior cervical osteosynthesis [23]. They had improved the technique with the use of an $\mathrm{H}$-shaped stainless steel plate, but one problem with stainless steel plates and screws is the artifacts that are produced in the postoperative CT or MRI. Recent reports in the literature have shown that good images can be obtained in the presence of titanium implants with both CT and MRI [15, 27]. The plates and screws used in the current study were made with titanium.

Since the first report, many articles have reported on the use of an anterior plate and screw fixation in stabilizing the lower cervical spine in traumatic, degenerative, tumorous, and infectious processes [3, $4,6,16,21,22]$. These studies all stress the benefits of allowing simultaneous neural decompression and immediate stability provided by the use of the anterior plate fixation. However, there are still some points of concern such as technical demands and the failure rate of hardware for acceptance of these techniques. Considering technical demands for using plates and screws, our personal results present that there is no evidence of any increase in surgical morbidity or mean operative time by using them. In some patients treated with a plating system, minor symptoms like increased neck pain, foreign body sensation on swallowing and dysphagia were noted, but presented transient. There were four cases of hardware failure: two cases of screw breakage and two cases of screw back-out, all of which occurred only in the patients treated with BNPS (group 2). Based on these results, MLPS appeared to be superior to BNPS in terms of mechanical strength of hardware. There has been no report comparing biomechanical strength between these two specific systems (Top and Orion). Recently, Ceddia and his colleagues have reported the clinical results of the comparison study between the Caspar and Lemaire systems of BNPS and MLPS of Morscher [10], in which they also conclude that hardware systems failure are more likely to occur in the patients treated with BNPS. The mechanism of higher hardware failure rate with BNPS than MLPS still remains unknown. In the present study, all cases 
Table 5. Surgical complication***

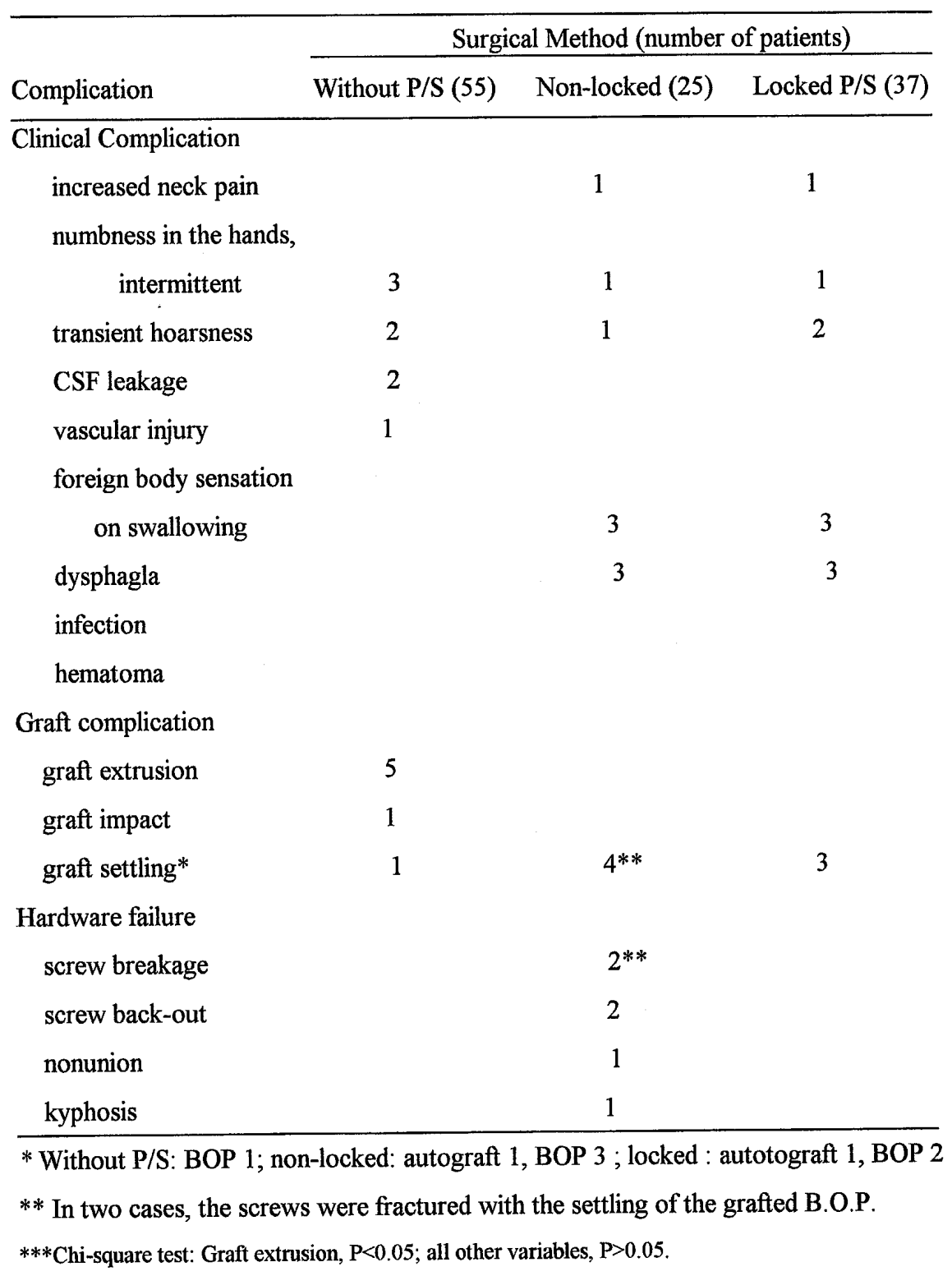

\section{Axial load}

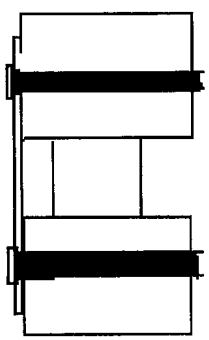

Immediate postoperative state

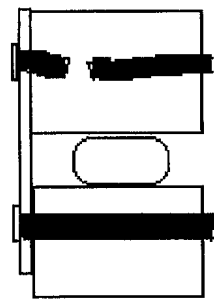

Settling of graft

Fracture of a bicortical screw
Figure 3. Hinge effect upon a breakage of bicortical screw exerted by axial load on the spine and settling of a intervertebral graft material 
of screw breakage occurred in the patients presenting graft settling, and a recent biomechanical study of the Caspar plate and the Cervical Spine Locking Plate system in a cadaveric model revealed that the Caspar of BNPS provided greater stability than fixation with MLPS [11]. Considering these two results in concert, it could be speculated that the settling of a graft might exert harmful effects on BNPS enough to break the bicortical screws in our series, because the bicortical screws which had greater stability and penetrated into both the anterior and posterior cortex might be relatively more vulnerable to the axial load than the monocortical screws while a graft was settling (Figure 3). However, the results of the biomechnical study with different systems could have been extrapolated to this speculation. A proper biomechanical evaluation and comparison of the systems used in the present study must be needed to elucidate the exact mechanism.

Two cases of screw back-out were also observed only in group 2. Based on the radiographic followup, screw back-out might develop when a screw did not pierce the dorsal cortex of the cervical spine during anterior cervical procedure. In BNPS, the fixation screws require piercing the dorsal cortex but not significantly violating the canal. We routinely confirmed the dorsal cortex purchase of screws by Carm X-ray monitor during the operation. Eventually the mean operative time for BNPS was longer than for MLPS (94 $\mathrm{min}$ vs. $79 \mathrm{~min}$ ). In our series, there was no case of screw back-out in group 3. However, although monocortical locked plates and screws are used, a screw can be backed-out, if the instrumentation is performed in severe osteoporosis, or a metal plate is placed over an intact vertebral disc.

It is well known that anterior cervical plating holds the graft under compression, facilitating bone healing. When the bone graft is placed with the cortical surface facing anteriorly and laterally, the plate can be more secured to the graft using a centrally placed screw, which stabilizes the plate for placement of peripheral screws into adjacent vertebral bodies, thereby inhibiting possible graft migration [18]. In the present study, there was no case of graft migration in the patients treated with a plating system. However, one case of non-union was observed in group 2 , in which a graft material was used with B.O.P., while there was no non-union case in group 1 or 3 . The overall fusion rate was $99 \%$.

In our series, we used three kinds of graft material, autograft from the iliac crest, allograft, and B.O.P., and 8 cases of graft settling have occurred, 2 in the patients treated with autograft and 6 in the patients with B.O.P. The incidence of the settling was about $9 \%$ in both autograft (2/23) and B.O.P.(6/64). The collapse of autograft bone is most frequently seen in elderly patients with osteoporotic bone [12], and both of our two cases were more than 60 years old as well. It has been reported that the advantages of B.O.P are its strength, excellent tolerance and the fact that it will not lose its shape, in addition to general advantages of a synthetic graft like early postoperative ambulation, short hospital stay and no pain at the donor site [20]. B.O.P. biocopolymere synthetic graft has been evaluated and followed up for 6 to 30 months in 100 cervical spine diseases by Brotchi and his colleagues [5]. Contrary to the results of our study, they reported that there was no compression of the graft, or other graft complications noted, although the surgical procedure they used was similar to ours. In general, the majority of the patients with graft settling are asymptomatic and do not require reoperation, and in our series no patient with it required reoperation either, even if screw breakage was accompanied in most of them. However, because of the possibility of graft collapse and subsequent screw breakage and reoperation, B.O.P. could not be recommended as a graft material in anterior cervical procedure using a plating system. The usefulness of B.O.P. in anterior cervical procedure must be verified again in a controlled clinical study. In the mean time, there was no significant graft complication in the patients using fibular allograft.

In summary, it appears that use of a plating system in anterior cervical fusion does not increase surgical morbidity in spite of its technical demands compared to anterior cervical fusion without a plating system, and more likely to offer postoperative stability in the 
spine and early ambulation without a rigid external brace. Use of a proper plating system and graft material may be an important factor to achieve the least surgical morbidity in anterior cervical fusion. In this respect, a monocortical locked plate screw system appears to be more proper than a bicortical nonlocked plate screw system, and fibular allograft can be a good alternative for a graft material in anterior cervical fusion.

\section{ACKNOWLEDGMENT}

This study was supported in part by the Catholic Medical Center. We would like to acknowledge the assistance of Ms. B. Y. Han in the preparation of the manuscript.

\section{REFERENCES}

1. Bailey RW, Badgley CE: Stabilization of the cervical spine by anterior fusion. J Bone Joint Surg Am 42A: 565-624, 1960

2. Boccanera L, Laus M: Osterosynthesis of the cervical spine with an anterior plate. Ital J Orthop Traumatol 15: 287-294, 1989

3. Bohler J, Ganderhak T: Anterior plate stabilization for fracture dislocations of lower cervical spine. J Trauma 20: 3, 1980

4. Bremer AM, Nguyen TQ: Internal metal plate fixation combined with anterior interbody fusion in cases of cervical spine injury. Neurosurgery 12: 649-653, 1983

5. Brotchi J, Levivier M, Raftopoulos C, Baleriaux D, Noterman J: Utilisation D'un greffon synthetique, le biocopolymere B.O.P., dans les abords anterieurs du rachis cervical. Esperience de 100 cas. Rachis 1: 367-372, 1989

6. Cabanela ME, Ebersol MJ: Anterior plate stabilization for bursting teardrop fractures of the cervical spine. Spine 13: 888-891, 1988

7. Caspar W: Anterior cervical fusion and interbody stabilization with the trapezoidal osterosynthetc plate technique: Aesculap Scientific Information, Tuttlingen, Aesculap-Werke-AG, 1986
8. Caspar W, Barbier DD, Klara PM: Anterior cervical fusion and Caspar plate stabilization for cervical trauma. Neurosurgery 25: 491-502, 1989

9. Caspar W, Harkey HL: Anterior cervical fusion. Caspar osteosynthetic stabilization. In: Young PH (ed):Microsurgery of the Cervical Spine. New York, Raven Press pp109-142. 1991

10. Ceddia A, Carraturo S, D'Angelo V, Rotondo SG: Anterior fixation of cervical spine. Bicortical screw-plate vs. monocortical selflocking systems (Abstr.) : 13th Annual Meeting of Section on Disorders of the Spine and Peripheral Nerves, 1997, p151

11. Clausen JD, Ryden TC, Traynelis V, Sawin PD, Dexter F, Goel VK: Biomechanical evaluation of Caspar and cervical spine locking plate systems in a cadaveric model. J Neurosurg 84: 10391045,1996

12. Cloward, RB: Complications of anterior cervical disc operation and their treatment. Surgery 69: 175-782, 1971

13. Cloward RB: The anterior approach for removal of ruptured cervical disks. J Neurosurg 15: 602617,1958

14. Cloward RB: Treatment of acute fractures and fracture-dislocations of the cervical spine by vertebral-body fusion. J Neurosurg 18: 201-209, 1961

15. Ebraheim NA, Coombs R, Rusin JJ, Jackson WT: Reduction of postoperative CT artifacts of pelvic fractures by the use of titanium implants. Orthopaedics 13: 1357-1358

16. Gasman J, Seligson D: The anterior cervical plate. Spine 8: 700-707, 1986

17. Hoff JT, Wilson CB: Microsurgical approach to the anterior cervical spine and spinal cord. Clin Neurosurg 26: 513-528, 1979

18. Karasick D: Anterior cervical spine fusion : struts, plugs, and plates. Skeletal Radiol 22: 8594, 1993

19. Levi L, Wolf A, Rigamonti D, Raghed J, Mirvis S, Robinson WL: Anterior decompression in cervical spine trauma: does the timing of surgery affect the outcome? Neurosurgery 29: 216-222, 
1991

20. Lozes G, Fawaz A, Cama A, Krivosic I, Devos P, Herlant M, Sertl GO, Clarisse J, Jomin M: Discectomies of the lower cervical spine using interbody biopolymere (B. O. P.) implants. Acta Neurochir 96: 88-93, 1989

21. Meyer PR: Surgery of Spine Trauma. New York, Churchill Livingstone, 1998

22. Oliveira JC: Anterior plate fixation of traumatic lesions of the lower cervical spine. Spine 12: 324-329, 1987

23. Orozco R, Llovet J: Osteosintesis en las fracturas del raquis cervical. Rev Ortop Traumatol 14: 285-288, 1970

24. Randle MJ, Wolf A, Levi L, Rigamont D, Mirvis S, Robinson W, Bellis E, Greenberg J, Saleman $\mathrm{M}$ : The use of anterior Caspar plate fixation in acute cervical spine injury. Surg Neurol 36: 181189, 1991

25. Ripa DR, Kowall MG, Meyer PR Jr, Rusin JJ: Series of ninety-two traumatic cervical spine injuries stabilized with anterior ASIF plate fusion technique. Spine 16: S46-S55, 1991

26. Robinson RA, Smith GW: Anterolateral cervical disk removal and interbody fusion for cervical disk syndrome. Bull Johns Hopkins Hosp 96: 223-224, 1955

27. Salvolaine ER, Ebraheim NA, Andreshak TG, Jaokson W: Anterior and posterior cervical spine fixation using titanium implants to facilitate magnetic resonance imaging evaluation. J Orthop Trauma 3: 295-299, 1989

28. Saunders RL, Bernini PM, Shirrefs TG, Jr, Reeves A: Central corpectomy for cervical spondylotic myelopathy: a consecutive series with long-term follow-up evaluation. J Neurosurg 74: 163-170, 1991

29. Smith GW, Robinson RA: Treatment of certain cervical spine disorders by anterior removal of the intervertebral disk and interbody fusion. J Bone Joint Surg Am 40A: 607-624, 1958

30. Stauffer ES, Kelly EG: Fracture-dislocations of the cervical spine: instability and recurrent deformity following treatment by anterior interbody fusion. J Bone Joint Surg 59A: 45-48, 1977

31. Tippets RH, Apfelbaum RI: Anterior cervical fusion with the Caspar instrumentation system. Neurosurgery 22: 1008-1013, 1988

32. Van Peteghem RK, Schweigel JF: The fractured cervical spine rendered unstable by anterior cervical fusion. J Trauma 19: 110-114, 1979

33. Verbiest H: Anterior operative approach in cases of spinal cord compression by old irreducible displacement or fresh fracture of cervical spine. J Neurosurg 19: 389-400, 1962

34. Verbiest H: Anterolateral operations for fractures and dislocations in the middle and lower parts of the cervical spine. Report of a series of fortyseven cases. J Bone Joint Surg Am 51A: 14891530,1969 


\section{Reviewer's comment : \\ Masakazu Takayasu \\ Department of Neurosurgery, Nagoya University School of Medicine Nagoya, Japan}

This is an interesting paper which shows results of three different methods for anterior cervical interbody fusion, i.e., simple fusion, locked and non-locked plating system in 117 patients operated upon by a single surgeon. They concluded with advantage of use of monocortical locked plate system. Major limitation of this study, however, is a way of classification of three treatment groups in chronological order besides its retrospective design, in which learning curve in surgical skills for the surgeons might affect the results. This study includes variety of patients with trauma, cervical spondylosis, OPLL and tumor with or without instability. Indication of surgical methods may be a little different in each disease. It is interesting that increased neck pain, foreign body sensation, or dysphagia were noted only in patients with a plating system. Detailed analysis of three kinds of graft materials such as iliac autograft, fibular allograft and biocompatible osteoconductive polymer would also be another interesting issue. 


\section{Reviewer's comment : \\ Junichi Mizuno \\ Department of Neurological Surgery, Aichi Medical University Aichi, Japan}

This paper well documented the clinical differences in anterior cervical interbody fusion with or without plating systems. This paper is essentially composed of three paragraphs. The first one is that there was no significant difference in neurological improvement either by simple fusion or by fusion with plating systems, although the neck pain, dysesthesia in swallowing or dysphasia were observed more frequently in cases with a plating system. However, graft extrusion occurred more frequently in cases of simple fusion. Secondary, they compared a monocortical locked plate screw systems with a bicortical nonlocked plate screw systems. The former systems are thought to be superior to the latter systems based on the biomechanical strength. They reported four hardware failures of bicortical non-locked plate screw systems, whereas no such a failure occurred in cases with monocortical locked plate screw systems in their series. On the third conclusion, they referred the graft materials including autograft from the iliac crest, fibular allograft and biocompatible osteoconductive polymer. The latter two materials were good alternatives for a graft material, because they provided good fusion as well as eliminating pain on the donor site. However, they did not recommend use of biocompatible osteoconductive polymer together with a plating system because of graft collapse and subsequent screw breakage.

Spinal instrumentation has become popular in the spinal surgery. It provides an immediate rigid internal stability and facilitates early return to work. However, it also contains several serious pitfalls including associated neck pain, hardware failure or graft collapse and settling. To avoid these complications, one must select the proper procedure and materials to each patient, which the authors stressed in the text. Therefore, this paper is worthwhile reading for all spinal surgeons. 